\title{
Leader
}

\section{Genital herpes, "the new paradigm"}

\author{
Stephen Taylor, Susan Drake, Deenan Pillay
}

The use of new molecular and serological assays has allowed fresh insights into the natural history of genital herpes. While formerly it was viewed as an initial symptomatic episode followed by clearly identifiable recurrences, studies have now shown that it is a chronic infection during which virus is frequently shed from mucosal surfaces, either in the absence of symptoms or with symptoms not ascribed to herpes simplex virus (HSV). Antiviral drugs can play a major role in reducing morbidity associated with this infection. However, progress with vaccine trials has been disappointing. We shall review some of the recent advances in the diagnosis and treatment of this important condition.

\section{Natural history}

Oral herpes labialis usually occurs as a result of infection by HSV type 1, whereas genital herpes can result from infection with either type 1 (HSV-1) or type 2 (HSV-2). Both types establish latency within the dorsal root ganglia innervating the mucocutaneous areas involved in the acute infection. The risk of symptomatic recurrence of genital herpes caused by HSV-1 within the first year is approximately $50 \%,{ }^{1}$ compared with $95 \%$ for HSV-2, with a mean monthly recurrence rate for recognised symptomatic episodes of 0.43 for men and 0.33 for women. ${ }^{1}$

Worldwide data reveal that most countries have a higher prevalence of HSV-2 genital herpes than HSV-1 genital herpes; however, studies of presentations to clinics in Europe show that up to $40 \%$ of first episodes of genital herpes are the result of type 1 infection. ${ }^{2}$ Despite the high prevalence of type 1 infection in primary episodes, $95-98 \%$ of recurrent cases are caused by type 2 infection.

\section{Asymptomatic shedding and unrecognised infection}

Recent virological studies of genital herpes (particularly those using sensitive polymerase chain reaction (PCR) techniques) show a significant degree of asymptomatic shedding (that is, the presence of HSV on an epithelial surface in the absence of symptoms) and shedding with unrecognised symptoms..$^{3-5}$ Of those seropositive for HSV-2, over $60 \%$ experience symptoms but do not associate them with genital herpes infection, $20 \%$ are asymptomatic, and only $20 \%$ have a diagnosis of genital herpes.
When infected women were followed prospectively by daily self swabbing for virus isolation, shedding was demonstrated on between $1-5 \%$ of days. ${ }^{6}$ By using PCR, the rate of asymptomatic shedding was noted to be about 3.5 times higher, reflecting an increased assay sensitivity. ${ }^{89}$ PCR studies have also confirmed that shedding occurs in clusters, particularly around symptomatic episodes, and it has been shown that women with frequent symptomatic recurrences are also at an increased risk of asymptomatic shedding. ${ }^{7}$ As expected, the rate of shedding is significantly lower for HSV-1 infections and shedding rates for both types are highest in the first 12 months after primary infection. ${ }^{10}$

The small amount of data available on asymptomatic shedding in men suggests a similar natural history, with the majority of asymptomatic reactivations occurring from intact penile skin. ${ }^{11}$

To date the infectious dose of virus necessary for transmission is unknown.

Transmission studies show that up to $70 \%$ of genital HSV infections are transmitted in the absence of symptoms in the source partner. ${ }^{12}$ The importance of asymptomatic shedding and unrecognised infection in the transmission and epidemiology of genital herpes is therefore evident. It follows that safer sexual practices undertaken only during symptomatic episodes will not necessarily prevent spread of this infection within the community.

\section{Epidemiology}

The seroprevalence of HSV 2 is increasing on a worldwide level. However, large variations are evident between different countries and also between different groups within the same country (fig 1).

Epidemiological studies show consistent patterns of risk for HSV-2 seropositivity. In nearly all populations it is higher in women and increases with the number of lifetime sexual partners. The chance of acquisition increases with age and varies according to ethnic origin and sexual orientation. For instance American data $^{2}$ showed a seropositivity rate of $80 \%$ in African American women aged 30-34 years in contrast to around $10 \%$ of white men aged 20-24 years. In the second US National Health and Nutrition Examination Survey (NHANES 1976-1980) $)^{13}$ the seroprevalence of HSV-2 antibody in the general population aged 15-74 


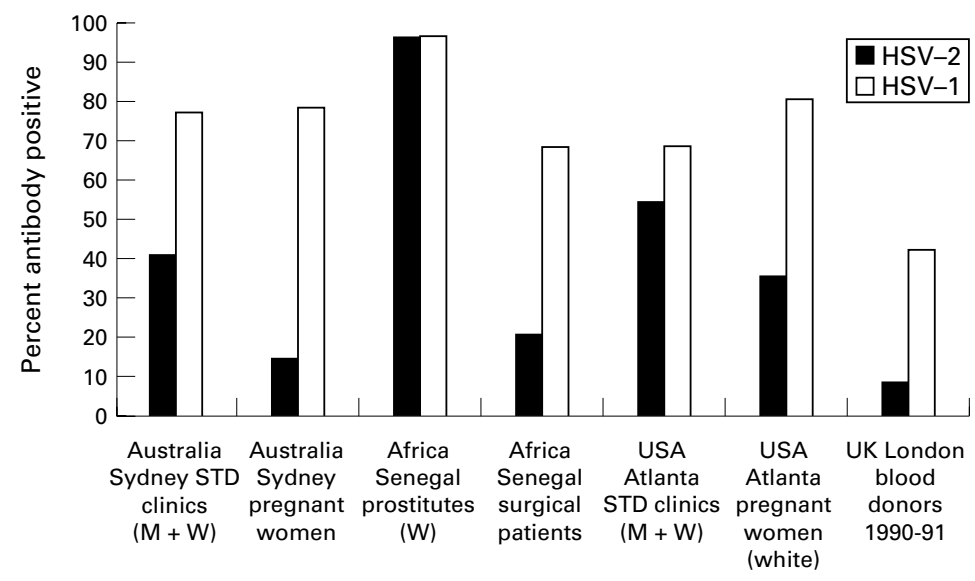

Figure 1 The seroprevalence of HSV-1 and HSV-2 by geographical area. Adapted from Nahmias et al. ${ }^{31}$

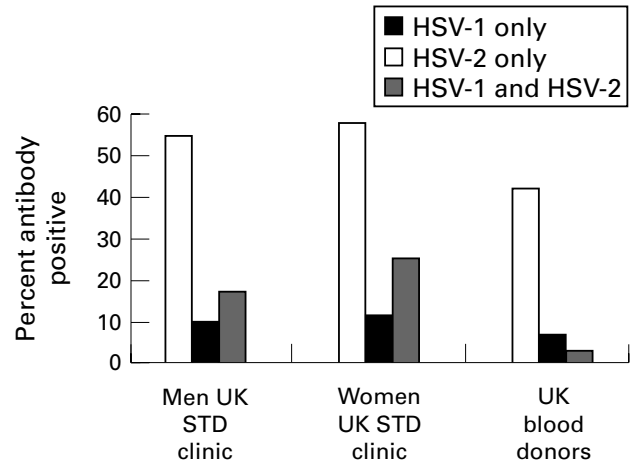

Figure 2 Seroprevalence of $H S V-1, H S V-2$, and combined infections within the United Kingdom. Adapted from Cowen et al. ${ }^{15}$

years for this period was $16.4 \%$, rising to $21.7 \%$ by $1990 .{ }^{14}$

United Kingdom figures ${ }^{15}$ from $1990-91$ in London show rates of $23 \%$ in STD clinic attenders $v 8 \%$ of blood donors (fig 2).

Although the reason for an increase in seroprevalence remains unclear, it is important to develop ongoing surveillance systems on a national basis to document changes in seroprevalence over time, and the corresponding impact on sexual health. Of particular concern is the coexistence of multiple sexually transmitted diseases and the possible role of genital HSV disease in the transmission of HIV.

\section{Diagnosis}

Virus culture, antigen detection, and PCR can be used for diagnosis of genital HSV infection.

Table 1 Potential use of type specific antibody test

\begin{tabular}{ll}
\hline Area of use & Comment \\
\hline Epidemiological studies & $\begin{array}{l}\text { To assess local seroprevalence, trends over time, } \\
\text { and the effect of interventional programmes } \\
\text { To identify those women at highest risk of } \\
\text { seroconversion during pregnancy and hence to } \\
\text { reduce neonatal herpes infections (see text) } \\
\text { Pregnancy }\end{array}$ \\
$\begin{array}{l}\text { Diagnosis of unrecognised infections in } \\
\text { symptomatic patients in whom standard tests fail } \\
\text { to provide a diagnosis. To establish diagnosis in } \\
\text { discordant partners. }\end{array}$ \\
$\begin{array}{l}\text { To identify suitable candidates and to monitor } \\
\text { these people for evidence of seroconversion }\end{array}$ \\
Cost-benefit studies required to evaluate role of \\
antivirals in reducing transmission.
\end{tabular}

Virus culture remains the standard test of choice for patients with active lesions. A well taken swab from the affected area, transported in viral transport medium without great delay, gives a very high sensitivity and specificity. In addition, culture of the virus allows viral typing and antiviral susceptibility testing if required. HSV antigen tests offer an alternative to conventional cell culture, but these commercial assays are of variable sensitivity and specificity. ${ }^{16}$ They are less sensitive than culture for cervical and urethral swabs. At present, such tests cannot distinguish between HSV-1 and HSV-2 infections.

PCR is the most sensitive test currently available $^{7}$ and is better for detection of asymptomatic shedding, but its place in the routine diagnosis of HSV is not yet clear.

Every patient with genital herpes should receive at least one laboratory confirmed diagnosis with virus typing so that they can be given important prognostic information about recurrences.

\section{HSV type specific antibody testing}

The majority of the antibody to HSV infection is raised against HSV surface glycoproteins, of which there are 11 . Of these, glycoproteins gB, $\mathrm{gC}, \mathrm{gD}$, and $\mathrm{gE}$ trigger potent immune responses. However, some epitopes on these glycoproteins are common to both type- 1 and type-2, causing a significant degree of cross reactivity with existing commercial assays. In contrast, there is no known cross reactivity between glycoprotein gG1 in HSV-1 and gG2 in HSV-2, and several detection assays using native purified or recombinant $\mathrm{gG} 1$ or $\mathrm{gG} 2$, or both, have been developed and validated. ${ }^{17-26}$ Western blot is the method which has been most extensively characterised; however, is not widely available in the United Kingdom. Commercial assays based on gG antibody detection are under development. It should be noted that while serological tests may be type specific they are not site specific and do not necessarily confirm a diagnosis of genital herpes.

How should these type specific tests be used? Possibilities are shown in table 1 . Perhaps the clearest indication for testing is in pregnant women at risk of acquiring infection in the last trimester of pregnancy. The definitive study published to date examined 7046 pregnant women in the USA. ${ }^{27}$ This showed that approximately $2 \%$ of susceptible women will acquire HSV infection during pregnancy. Of the 94 women who became seropositive, only 34 were symptomatic. The risk of seroconversion was highest in those women who were seronegative for both HSV-1 and HSV-2, with a risk of seroconversion for either virus of $3.7 \%$. Being positive for HSV-1 offered a degree of protection, with a risk for acquiring HSV-2 of $1.7 \%$ (none of those who were HSV-2 positive seroconverted to type 1). Most interesting was the fact that in those women who acquired infection in early pregnancy, and therefore seroconverted, there was no associated increased risk of neonatal morbidity or congenital infection, although this does not rule out very early fetal loss. However, in those 
women in whom infection was acquired near to the time of labour (nine women), neonatal HSV infection occurred in four infants, one of whom died. Therefore serological testing of women (and their partners) in the latter half of pregnancy may identify those women most susceptible to HSV infection, so that appropriate counselling and risk reduction measures may be employed. It must be remembered that the incidence of neonatal herpes is far lower in the United Kingdom than in the USA, ${ }^{28}$ and extrapolation of these conclusions to the United Kingdom must be undertaken with caution. It should also be emphasised that orogenital contact in HSV-1 seronegative pregnant women does not constitute "safe sex," as neonatal infection can occur with either subtype. More widespread testing of high risk patients (for example, genitourinary clinic attenders) is problematic. Since HSV-2 infection is commonly asymptomatic yet remains stigmatised, the psychological harm of knowing one's HSV-2 status may outweigh any benefits.

\section{Antiviral treatment}

Aciclovir, valaciclovir, and famciclovir have all shown comparable virological and clinical efficacy in large scale, parallel group, double blind, placebo controlled trials. In patients with frequent recurrences, long term suppressive treatment dramatically decreases symptoms, both physical and psychological, and can be recommended. Patient initiated episodic treatment still has a place for those mild or infrequent attacks with a well defined prodrome. There remains a need to educate physicians on the use and benefits of oral antiviral drugs for the management of recurrent genital herpes.

\section{Vaccine development}

The most promising of the immunotherapeutic vaccines developed have used HSV glycoproteins as immunogens linked with a variety of adjuvants. Unfortunately the success demonstrated in guinea pig models has not been translated into success in controlled clinical trials in humans. ${ }^{29}$ Thus there are currently no immunotherapeutic vaccines available with proven efficacy. A new vaccine consisting of glycoprotein gD2 absorbed onto alum plus a second adjuvant (monophosphoryl lipid $\mathrm{A}$ ) is undergoing phase $2 / 3$ clinical trials.

Unfortunately, it appears that antibody responses themselves do not necessarily predict the effectiveness of vaccines, and cell mediated responses may be more relevant.

Prophylactic HSV vaccine development presents further difficulties, because to prevent infection replication must be halted almost immediately, before latency is established in the relative immunologically protected sensory neurones.

Molecular engineering has led to new approaches to vaccine development. Of particular interest is the disabled infectious single cycle (DISC) vaccine. The DISC virus is a replication defective virus (produced by creating essential gene deletions), capable of a single cycle of replication only. As the DISC virus contains most of the structural proteins which occur in wild-type virus it can stimulate a broader response than that induced with subunit vaccines. In addition, antigens can be presented in association with MHC class 1 molecules, thus also stimulating a broad cell mediated response. In animal models, HSV-2 DISC virus vaccine has shown high levels of protection. ${ }^{30}$ Initial safety and immunogenicity studies in man are ongoing and are awaited with interest.

\section{Conclusions}

Genital herpes is a common condition which is often misdiagnosed, unrecognised, and undertreated. Evidence suggests that transmission usually occurs when partners are shedding virus asymptomatically. Suppressive antiviral treatment is effective in reducing symptomatic recurrences and can be recommended in those patients suffering more than six to eight attacks a year. Intuitively it may also play a role in reducing transmission; however, this is not yet proven and clinical trials addressing this issue are in progress.

An accurate, type specific antibody test will soon be commercially available which will be useful in the management of individual patients and in epidemiological studies. Its widespread use will inevitably identify many more people seropositive for HSV-2. This will in turn increase demand for expensive antiviral drugs and appropriate counselling and support for those found to be infected. Genital herpes is still a condition that induces deep feelings of stigmatisation and distress, but morbidity and mortality is concentrated within the immunocompromised, and in neonates born to mothers with active lesions. Much careful thought about clinical priorities will be needed before widespread serological testing is employed. The current dilemma is in the need to reflect our new understanding of the natural history of this infection in the advice given to patients, without provoking enormous anxiety and creating unrealistic expectations of suppressive treatment. For the moment viral culture and typing from visible lesions remains the diagnostic method of choice.

1 Benedetti J, Corey L, Ashley R. Recurrence rates in genital herpes after symptomatic first-episode infection. Ann Intern Med 1994;121:847-54.

2 Mertz GJ, Weinberg A, Canto CL, et al. Epidemiology of genital herpes infections. Infect Dis Clin North Am 1993;7:825-39.

3 Barton SE, Wright LK, Link CM. Screening to detect asymptomatic shedding of herpes simplex herpes virus (HSV) in women with recurrent genital HSV infection. (HSV) in women with recurre

4 Barton SE, Davis JM, Moss VW. Asymptomatic shedding and subsequent transmission of genital herpes simplex virus. Genitourin Med 1987;63:102-5.

5 Corey L. The current trend in genital herpes. Progress in prevention. Sex Transm Dis 1994;21:38-44.

6 Brock BV, Selke S, Benedetti J. Frequency of asymptomatic shedding of herpes simplex virus in women with genital herpes. ЭAMA 1990;263:418-20.

7 Wald A, Zeh J, Selke S. Virological characteristics of subclinical and symptomatic genital herpes infection. $N$ Engl f Med 1995;333:770-5.

8 Cone RW, Hobson AC, Palmer J. Extended duration of herpes simplex virus DNA in genital lesions detected by polymerase chain reaction. F Infect Dis 1991;164:757-60. genital tract: implications for transmission. Herpes $\mathcal{F} 1997$;
girus the 4:30-5

10 Koelle DM, Benedetti J, Langenberg A. Asymptomatic reactivation of herpes simplex virus in women after the first episode of genital herpes. Ann Intern Med 1992;116:433-7. 
11 Wald A, Taylor L, Warren T. Subclinical shedding of herpes simplex virus in men with genital herpes [abstr]. San Agents and Chemotherapy, 1995.

12 Mertz GJ, Schmidt O, Jourden JL. Frequency of acquisition of first episode genital infection with herpes simplex virus from symptomatic and asymptomatic source contacts. Sex Transm Dis 1985;12:33-9.

13 Johnson RE, Nahmias AJ, Magder LS. A seroepidemiological survey of the prevalence of herpes simplex virus type 2
infection in the United States. N Engl f Med 1989;321:712.

14 Fleming DT, McQuillan GM, Johnson RE, et al. Herpes simplex virus type 2 in the United States, 1976 to 1994 . N Engl f Med 1997;337:1105-11.

15 Cowan F, Johnson A, Ashley R, et al. Antibody to herpes simplex virus type 2 as serological marker of sexual lifestyle in populations. BMf 1994;309:1325-33.

16 Kudesia G, Van Hegan A, Wake S. Comparison of cell culture with amplified enzyme immunoassay for diagnosing
genital herpes simplex infection. $\mathcal{F}$ Clin Pathol 1991;44: genital her.

17 Ashley R, Lee F, Coleman RM, et al. Detection of herpes simplex virus type 2 -specific antibody with glycoprotein $\mathrm{G}$ f Clin Microbiol 1985;22:641-4.

18 Lee FK, Pereira L, Griffin C. A novel glycoprotein for detection of herpes simplex virus type 1-specific antibodies. f Virol Methods 1986;14:111-18.

19 Ashley R, Militoni J, Lee F. Comparison of western blot (immunoblot) and glycoprotein G-specific immunodo enzyme assay for detecting antibodies to herpes simplex virus types 1 and 2 in human sera. 7 Clin Microbiol 1988;26:662-7.

20 Sanchez-Martinez D, Schmid DS, Whittington W. Evaluation of a test based on baculovirus-expressed glycoprotein $G$ for detection of herpes simplex virus type-specific antibodies. F Infect Dis 1991;164:1196-9.

21 Pellet PE. Expression of HSV-1 and HSV-2 glycoprotein G in insect cells by using a novel baculovirus expression vector. Virology 1991;182:229-38.
22 Ho DWT, Field PR, Irving WL. Detection of immunoglobulin $M$ antibodies to glycoprotein G-2 by western blot (immunoblot) for diagnosis of initial herpes simplex virus 2 genital infections. F Clin Microbiol 1993;31:3157-

23 Slomka MJ, Ashley RL, Cowan FM. Monoclonal antibody blocking tests for the detection of HSV-1 and HSV-2 specific humoral responses: comparison with western blot assay. F Virol Methods 1995;55:27-35.

24 Alexander D, Dinella R, Ashley R. Simultaneous use of glycoprotein $\mathrm{gB} 1, \mathrm{gH} 1, \mathrm{gD} 2$ and $\mathrm{gG} 2$ as antigens for a type-specific serological assay to diagnose prior to infection with HSV-1 or HSV-2. 96th General Meeting of the American Society of Microbiology, New Orleans, 1996 [abstract].

25 Ashley RL, Warford A, Gleaves C. Evaluation of the CHIRON RIBA HSV type-1/type-2 strip immunoblot assay (SIA) for typing of HSV antibodies (Ab) [abstr]. San Francisco: 35th Infectious Diseases Society, 1997.

26 Ashley RL, Wu L, Pickering JW, et al. Sensitivity and accuracy of glycoprotein g-based enzyme immunoassays for racy of glycoprotein g-based enzyme immunoassays for antibodies to herpes simpl $1998 ; 36: 294-5$.

27 Brown ZA, Selke S, Zeh J, et al. The acquisition of herpes simplex virus during pregnancy. $N$ Engl f Med 1997;337: $509-15$.

28 Whitley RJ, Corey L, Arvin A. Changing presentation of neonatal herpes simplex virus infection. I Infect Dis 1988;158:109-16.

29 Straus S, Wald A, Kost R, et al. Immunotherapy of recurrent genital herpes with recombinant herpes simplex virus type vaccine trial. F Infect Dis 1997;176:1129-34.

30 McLean CS, Erturk M, Jennings R, et al. Protective vaccination against primary and recurrent disease caused by herpes simplex virus (HSV) type 2 using a genetically disabled HSV-1. F Infect Dis 1998;170:1100-9.

31 Nahmias AJ, Lee FK, Beckman-Nahmias S. Seroepidemiological patterns of herpes simplex patterns in the world. logical patterns of herpes simplex patt 